\title{
The effects of taste adulteration, hypertonic, and hyperoncotic solutions on water ingestion in the gerbil*
}

\author{
DENNIS A. VANDERWEELE \\ Occidental College, Los Angeles, California 90041
}

\begin{abstract}
Mongolian gerbils (Meriones unguiculatus) were examined for components of thirst in the laboratory. The gerbil, reputed to be a desert-adapted rodent, was tested for its response to quinine adulterations of water, hypertonic solutions (1 $\mathrm{M}$ sodium chloride, $\mathrm{NaCl})$, and hyperoncotic solutions $(40 \% \mathrm{~W} / \mathrm{V}$ polyethylene glycol in isotonic saline, $\mathrm{PG}$ ). Both $\mathrm{NaCl}$ and $\mathrm{PG}$ were administered intraperitoneally. Gerbils accepted quinine when it was the only solution available and food was ad lib, but preferred distilled water to quinine if both were available. Both PG and $\mathrm{NaCl}$ produced increased water intakes in gerbils within the first $2 \mathrm{~h}$, postinjection. PG, however, produced the most reliable and largest increase in water consumption, illustrating that extracellular dehydration is probably a more significant thirst stimulus in gerbils.
\end{abstract}

The Mongolian gerbil (Meriones unguiculatus) is native to the semi-arid deserts and steppes of northern China, Korea, and Mongolia. The organism has evolved in this harsh environment and should show the physiological adaptations necessary for survival in xerophytic niches, environments with little free water. This paper analyzes some influences upon water consumption in this species.

Robinson (1959) questions the classification of the gerbil as a xerophyte on the basis of body temperatures; however, other researchers (Hudson, 1964; Boice \& Arledge, 1968) have classified the animal as desert-adapted on the basis of water utilization and intake. Also, it must be realized that the desert-adapted rodent does not have the same body-temperature, water-evaporation responses or problems that the desert-adapted camel does. Also, gerbils can concentrate electrolytes in urine very effectively, which represents another adaptation to xerophytic habitats.

To date, most studies on xerophytic rodents have assessed only water consumption, sources, and losses. Most studies are done in the observational framework in captivity, and Chew (1965) has pointed out that many animals drink more in captivity than predicted. Also, Miller (1957) has stressed the need for multiple measures of animal motivation in behavioral settings. For these reasons, an examination of some variables which affect

\footnotetext{
*Parts of this research were supported by an NDEA fellowship. The research was conducted in partial fulfillment of the doctoral degree requirements at the University of Maine at Orono, Maine. Special thanks should be given to Robert $M$. Abelson for his help in the preparation of this dissertation. Replication and extension of this paper was completed at the University of California at Los Angeles vith the support of an NIMH training grant (NH06415) to the Brain R esearch Institute and of NINDS Grant NS7687-05 to Donald Novin. Finally, parts of this paper were communicated at the 1971 meetings of The Eastern Psychological Association in New York City.
}

drinking in nondesert-adapted rodents was carried out on the gerbil.

When water is available to gerbils in the laboratory, they drink (Winkelmann \& Getz, 1962). These Es reported that gerbils consumed a mean of $0.039 \mathrm{~g}$ of water/g body weight per day. When the animals were water-deprived, weight losses occurred. However, extremely concentrated saline solutions were ingested by gerbils and could prevent weight loss. Other reports (Arrington \& Ammerman, 1969; Harriman, 1969; Kutscher, 1969) have also shown that gerbils drink water in the laboratory, but only two studies to date have demonstrated gerbils to be motivated to acquire water (VanderWeele, Abelson, \& Tellish, 1973; VanderWeele \& Abelson, 1973). These experiments found that gerbils would barpress on both response- and time-contingent schedules of reinforcement for water.

The present study examines the effects of taste alteration (quinine adulteration) and the effects of challenges of extra- and intracellular dehydration procedures on the water consumption of gerbils. The above procedures produce alterations of drinking in other rodents.

\section{METHOD}

\section{Subjects and Apparatus}

Sixty-eight experimentally naive gerbils were used. Gerbils were obtained from breeding colonies maintained by the E. Thirty-eight Ss were male and all animals were 4 to 8 months old.

All were housed in cages $20.3 \times 25.4 \mathrm{~cm}$. Cages were metal and had glass eudiometer tubes protruding through the cage fronts (Fisher 50- and 100-ml tubes were used). Food was Purina Lab Chow Blocks and the water was distilled. Both were weighed daily to determine consumption. Quinine adulterations were achieved with quinine sulfate (W/V solutions), and sodium chloride and polyethylene glycol were used to assess drinking following dehydration stresses. 


\section{EXPERIMENT I}

\section{Procedure}

Fresh portions of food and water were administered to all Ss daily for 20 days. This constituted the baseline period, and consumptions of water were quite stable for all Ss; 0.04 to $0.10 \mathrm{~g} / \mathrm{g}$ body weight per $24 \mathrm{~h}$ were the range of mean daily water intakes.

After the baseline, all Ss received $0.03 \%$ quinine-sulfate solution as the only solution available for ingestion for 2 consecutive days. Subsequently, Ss were returned to distilled water which was available for 10 days, after which they were again given quinine-sulfate solutions $(0.067 \%)$ for 2 days. On both quinine exposures, quinine was the only available solution for drinking-forced-choice paradigm-and food remained ad lib. In addition, two Ss (one male, one female) were maintained throughout the entire experiment with food ad lib and both water and quinine available. Water was distilled and quinine was a $0.067 \%(\mathrm{~W} / \mathrm{V})$ solution, each available in a tube randomly alternated to avoid position preferences.

This experiment, and the following one, were conducted in a small quiet room. The temperature was maintained at $20^{\circ} \pm 1^{\circ} \mathrm{C}$ and the relative humidity averaged $32 \% \pm 6 \%$. Dim overhead lighting was provided from 0600 to 1800 daily, and a large fluorescent fixture was on from approximately 0800 to 1600 daily.

\section{Results}

When quinine alone was available for ingestion, all gerbils consumed the solutions. The 2-day means for both concentrations used showed that quinine consumption did not differ from consumption of distilled water $(p>20)$. Mean consumption was $6.2 \mathrm{ml} / 24 \mathrm{~h}$ for water, $5.8 \mathrm{ml} / 24 \mathrm{~h}$ for the $0.03 \%$ solution, and $5.7 \mathrm{ml} / 24 \mathrm{~h}$ for the $0.067 \%$ solution of quinine sulfate. The fact that the gerbil can sense the quinine adulteration was suggested by the initial decrement on the first day of each exposure (see Table 1). Also, the two Ss given a choice between quinine-sulfate solution and distilled water preferred distilled water; daily water intake was $6.0 \mathrm{ml}$, while only $1.2 \mathrm{ml}$ quinine sulfate was ingested (20-day means). Both figures represent means and were grouped regardless of the tube or side in which the solution was offered. The finding that water is preferred over quinine but that quinine is ingested normally when food is ad lib indicate that the thirst of the gerbil in the laboratory situation is not simply spontaneous drinking due to the presence of water.

Table 1

Mean Consumptions of Quinine or Water in the Three Conditions of Experiment I

\begin{tabular}{lccc}
\hline & \multicolumn{3}{c}{ Mean Fluid Consumption (mL) } \\
\cline { 2 - 4 } Condition & $\begin{array}{c}\text { Combined } \\
\text { Days 1-2 }\end{array}$ & $\begin{array}{c}\text { Exposure } \\
\text { Day 1 }\end{array}$ & $\begin{array}{c}\text { Exposure } \\
\text { Day 2 }\end{array}$ \\
\hline $\begin{array}{l}\text { Quinine }(.03 \%) \\
\text { Available } \\
\begin{array}{l}\text { Quinine }(.067 \%) \\
\text { Available }\end{array}\end{array}$ & 5.85 & 5.62 & 6.08 \\
$\begin{array}{l}\text { Baseline Water } \\
\text { Consumption }\end{array}$ & 5.75 & 5.15 & 6.35 \\
\hline
\end{tabular}

Note-None of the mean differences was significant, $p>.20$

\section{EXPERIMENT II}

The initial experiment demonstrated that the gerbil drinks water in the laboratory and will accept a quinine adulteration of the water when this is the only solution available and food is ad lib. The present experiment assessed the effects of cellular dehydration and extracellular dehydration processes on the water consumption of the gerbil. This represents the first assessment of the effects of hypertonic sodium chloride and hyperoncotic polyethylene glycol on gerbil water ingestion.

\section{Procedure}

Fifty-seven gerbils, 26 of which had been used in Experiment I, were used. Thirty-two Ss were male. The Ss were housed as described in the first study (with glass tubes and distilled water again available). Food was ad lib Purina Lab Chow Blocks.

All Ss, except for four which were tested for the combinative effects of the drugs, were tested as follows: Thirty-five Ss were initially tested with $1 \mathrm{M}$ sodium chloride $(\mathrm{NaCl})$, while the remaining Ss were sham-injected (the needle was inserted, but no fluid was delivered). All Ss were weighed prior to injection, and those receiving the hypertonic $\mathrm{NaCl}$ solution were given a $1 \%$ body-wejght dose, intraperitoneally. Sham-injected and $\mathrm{NaCl}$-injected Ss were then measured for water consumption, 2 and $4 \mathrm{~h}$ postinjection. All Ss ranged from 53 to $86 \mathrm{~g}$ in body weight, and injections were made at 0900 on both days. The following day, all Ss were again weighed and those receiving $\mathrm{NaCl}$ on the day previous were given the sham injections. Ss which had received the sham injection on the previous day received injections of polyethylene glycol (PG was a 40\% W/V solution in a carrier of isotonic saline, administered intraperitoneally at a dosage of $1 \%$ body weight). Water was again measured, as on the day before, for all Ss. The four Ss which received both drugs received the $\mathrm{NaCl}$ prior to $\mathrm{PG}$ and simply received the same dosages as the other Ss, only in combination. Measuring for these four Ss was on the same schedule as for the other Ss.

\section{Results}

Both $\mathrm{NaCl}$ and $\mathrm{PG}$ were shown to cause significant increases in water consumption over the first 2 -h period, postinjection. Differences were significant, compared to sham-injected baseline consumption of water $(p<.05$ for all comparisons). These differences are demonstrated in Fig. 1, which shows that the drinking subsides within the first $2 \mathrm{~h}$, postinjection. The average latency to drink (interval following infusion before the initiation of drinking) was $23 \mathrm{~min} \pm 3.4 \mathrm{~min}$ for $\mathrm{NaCl}$ and $73 \mathrm{~min} \pm$ $11.0 \mathrm{~min}$ for $\mathrm{PG}$, mean \pm SD in both cases, and this was determined by visual observation. Sham-injected Ss' latency to drink was $59 \mathrm{~min} \pm 14.3 \mathrm{~min}$.

\section{DISCUSSION}

The present study again demonstrated that gerbils drink water in the laboratory. Experiment I illustrated that gerbils would ingest water, despite quinine adulteration, at a rate nonsignificantly different from unadulterated water. It seems that gerbils can sense the presence of quinine as Ss which were allowed a choice between it and water, preferred water at a ratio of 
almost five to one. This motivational measure, combined with previous findings (VanderWeele, Abelson, \& Tellish, 1973; VanderWeele \& Abelson, 1973) all demonstrate that gerbils are motivated to drink; this agreement is not always the case, as pointed out by Miller (1957). The motivation to acquire water corresponds with Winkelmann and Getz's (1962) report of weight loss and physical deterioration if water is withheld from the gerbil. These findings combine to show that gerbils, despite survival in harsh environments, have a definite physiological need for water, do respond to this need by drinking, and are motivated to acquire new operant behaviors for water rewards in the laboratory.

Finally, both hypertonic $\mathrm{NaCl}$ and hyperoncotic PG were demonstrated to promote increased water ingestion in the gerbil. These two stimuli have been shown to produce cellular dehydration $(\mathrm{NaCl})$ and extracellular dehydration (PG), in the white rat. Further, the two stimuli have been shown to produce a greater than simple additive effect when administered in combination in the white rat (Blass \& Fitzsimons, 1970). Gerbils given equal dosages of extracellular (PG) and cellular-dehydrating agents $(\mathrm{NaCl})$, however, drink considerably more in response to the extracellular stimulus. The reverse situation appears to be true in the white rat (Blass \& Fitzsimons, 1970). Almli (1971) has reported that, in rats, hypervolemia accompanies the onset of drinking induced by $P G$, rather than the proposed hypovolemia cited by Blass and Fitzsimons. Almli then attributed PG-induced drinking to cellular dehydration, rather than to hypovolemia. This explanation would not influence the conclusions reached here about water intake in the gerbil, as gerbils showed a latency to drink which was far longer than that reported necessary for the development of hypovolemia in the rat in response to $\mathrm{PG} .^{1}$

Between rats and gerbils, the sensitivity differences to the different dehydrating agents could be explained by reference to the Schmidt-Nielsens's (1949) work on the kidney of the desert-adapted rodent. Excess salt and other electrolytes can be voided from the xerophytic rodent's body with little attendant water loss, making solute loads a minor thirst stimulus. The gerbil does not lose excessive amounts of water in urine formation and concentration, despite the challenge of increased electrolytes. Indeed, gerbils can gain weight on salt water equiosmotic to sea water and ad lib food (Winkelmann \& Getz, 1962).

In conclusion, thirst or motivation to acquire and consume water in the gerbil appears similar to that found in the white rat. Rats and gerbils both respond to hypertonic $\mathrm{NaCl}$ and hyperoncotic $\mathrm{PG}$ injections by increasing water intake, and both species respond at a greater than simple additive effect to combinations of these dehydrating agents. Further, gerbils will accept quinine adulteration and perform operant tasks to

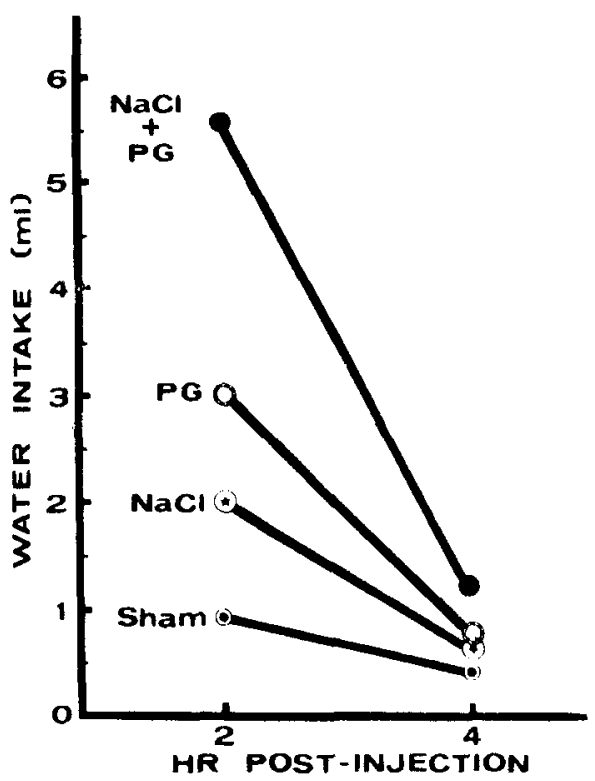

Fig. 1. Water ingestions following injections of two dehydrating agents (hypertonic sodium chloride, $\mathrm{NaCl}$, and hyperoncotic polyethylene glycol, PG) administered singly and in combination at a dosage level of $1 \%$ body weight in the Mongolian gerbil.

obtain water. The major difference in the drinking of the gerbil appears to be that PG promotes the most reliable fluid-intake increase, probably due to extracellular dehydration. This lat ter statement does not appear to be true of the rat.

\section{REFERENCES}

Almli, C. R. Hypervolemia at the polyethylene glycol induced onset of drinking. Physiology \& Behavior, 1971, 7, 369-373.

Arrington, L. R., \& Ammerman, C. B. Water requirements of gerbils. Laboratory A nimal Care, 1969, 19, 503-505.

Blass, E. M.. \& Fitzsimons, J. T. Additivity of effect and interaction of a cellular and extracellular stimulus of drinking. Journal of Comparative \& Physiological Psychology, 1970, 70 . 200-205.

Boice, R., \& Arledge, J. G. Water requirements of gerbils and kangaroo rats in the laboratory. Psychological $R$ eports, 1968 23, 1063-1069.

Chew, R. M. Watex metabolism of mammals. In W. V. Mayer and R. G. Van Geider (Eds.), Physiological mammalogy II. New York: Academic Press, 1965.

Harriman, A. E. Food and water requirements of Mongolian gerbils as determined through self-selection of diets. The American Midland Naturalist, 1969, 82, 149-156.

Hudson, J. W. Water metabolism in desert mammals. In W. J. Wayner (Ed.), Thirst. New York: Pergamon Press, 1964.

Kutscher, C. Species differences in the interaction of feeding and drinking. Annals of the New York Academy of Sciences, $1969,157,539-552$.

Miller, N. E. Experiments on motivation. Studies combining psychological, physiological, and pharmacological techniques. Science, 1957, 126, 1271-1278.

Schmidt-Nielsen, B., \& Schmidt-Nielsen, K. The water economy of desert mammals. The Scientific Monthly, 1949, 69 180-185.

VanderWeele, D. A., Abelson, R. M., \& Tellish, J. A. A comparison of ratio behavior in the gerbil and white rat. Bulletin of the Psychonomic Society, 1973, 1, 62-64.

VanderWeele, D. A., \& Abelson, R. M. Selected schedules of reinforcement in the Mongolian gerbil. Psychological Reports, $1973,33,99-104$ 
Winkelmann, J. R., \& Getz, L. L. Water balance in the Mongolian gerbil. Journal of Mammalogy, 1962, 43, 150-154.

\section{NOTE}

1. Almli and Weiss have recently reported that, although gerbils drink following water deprivation and dehydration produced by $\mathrm{PG}, \mathrm{NaCl}$ injections, which produced increases in water intake in guinea pigs and rats, did not increase drinking in the gerbil. The present experim ent has shown drinking in gerbils in response to hypertonic $\mathrm{NaCl}$; however, the increased drinking occurred mainly within the first $1 / 2 \mathrm{~h}$ following injection and was far below that seen in the rat (unpublished observation). The present experiment concurs with Almli and Weiss in the reliability of PG-induced drinking in the gerbil. Almli and Weiss's paper appeared in the program of the Midwestern Psychological Association convention of May 1974, in Chicago, Illinois.

(Received for publication April 9, 1974; accepted July 3,1974 .) 